\title{
Targeted Questionnaire Development
}

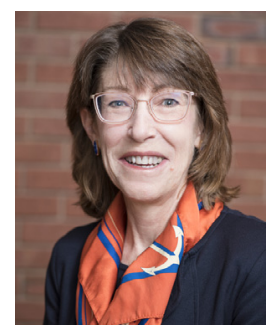

Last year we implemented a new article type category for Questionnaire Development. These can be found under the Collections tab on the jneb.org website.

The Development and Validation of a Military Eating Survey includes 43 eating habits and 90 mediating behavior items. ${ }^{1}$ The 14 habit scales include hunger, satiety, food craving, meal pattern, restraint, diet rigidity, emotional eating, fast/slow eating rate, environmental triggers, situational eating, supplement use, and food choice; the 8 mediating factor scales include body composition strategy, perceived stress, food access, sleep habits, military fitness, physical activity, military body image, and nutrition knowledge. While only appropriate for military personnel, the process that was used can provide a guideline for other questionnaire development.

Similarly, there are 2 Questionnaire Development papers in this issue: Development and inter-rater reliability of a street food stand assessment tool $^{2}$ and Development of a 24-hour movement behavior questionnaire for youth: process and a reliability testing. ${ }^{3}$ The street food stand assessment was developed in Mexico with street food stands in Mexico City. Again, a unique target that doesn't apply to other areas, but the authors provide an interesting lens into the issues with food access and availability. The youth movement questionnaire includes 19 questions in 5 categories: general information, sleep and nap, active transportation-related activity, school life, and free-time activities for Korean adolescents aged 13 to 17 years. I was amused that while pilot-testing the questionnaire with youth, 1 responded: "Is there anyone watching TV or DVD these days? I don't have a TV at home." Of course not. They use their phones.

One questionnaire development paper that was published in November is the Development of Food Literacy Assessment Tool Targeting LowIncome Adults. ${ }^{4}$ Food literacy is becoming more popular over the last few years. I always like to read the items for each category and see how I'd do. The 2 in the nutrition knowledge section of this questionnaire relate to soda: how many calories and how many grams of sugar. I seldom drink soda so this is not on my radar. However, it probably is on the radar of adults from low-income environments. Indeed, food insecurity increased the odds of habitual sugarsweetened beverage consumption in Hispanic/Latino WIC families in New York.

While the JNEB collection of Questionnaire Development is a valuable resource, we all know these are specific to the program aims and target population. Auld et al outline this issue in their 2017 article Confirming the Reliability and Validity of Others' Evaluation Tools Before Adopting for Your Programs ${ }^{5}$ much better than I can. I know it is easier to adopt another's work that has gone through rigorous development and testing, but you may not be pleased or satisfied with the results. And it certainly may be challenging when you go to publish. However, you will have a better program or intervention evaluation and you might get another publication if you develop a questionnaire specific to your needs!

Karen Chapman-Novakofski $P h D, R D N$

Editor-in-Chief

\section{REFERENCES}

1. Cole RE, Jayne JM, O'Connor K, McGraw SM, Beyl R, DiChiara AJ, Karl JP. Development and validation of the military eating behavior survey. $J$ Nutr Educ Behav. 2021;53:798-810.

2. Rosales Chavez JB, Jehn M, Lee RE, Ohi-Vachaspati P, Bruening M. Development and inter-rater reliability of a street food stand assessment tool. J Nutr Educ Behav. 2021;53:1072-1080.

3. Song Y, Yoon YJ, Lee HJ, Spence JC, Jeon JY. Development of a 24-hour movement behavior questionnaire for youth: process and reliability testing. $J$ Nutr Educ Behav. 2021;53:1081-1089.

4. Hemmer A, Hitchcock K, Lim YS, Kovacic MB, Lee SY. Development of food literacy assessment tool targeting adults with low income. J Nutr Educ Behav. 2021;53:966-976.

5. Auld G, Baker S, McGirr K, Osborn KS, Skaff P. Confirming the reliability and validity of others' evaluation tools before adopting for your programs. J Nutr Educ Behav. 2017;49:441-450. 